Check for updates

Cite this: J. Mater. Chem. A, 2018, 6, 823

Received 20th November 2017 Accepted 7th December 2017

DOI: $10.1039 / c 7 t a 10222 d$
Radiation-induced grafting of a butyl-spacer styrenic monomer onto ETFE: the synthesis of the most alkali stable radiation-grafted anionexchange membrane to date $\dagger$

\author{
Julia Ponce-González, (D) * Imad Ouachan, (D) John R. Varcoe (ID \\ and Daniel K. Whelligan
}

rsc.li/materials-a

\begin{abstract}
An ETFE-(poly(ethylene-co-tetrafluoroethylene))-based radiationgrafted anion-exchange membrane (AEM) containing a butyl-spacer between the benzene and the methylpyrrolidinium groups (C4-AEM) had double the ex situ alkali stability at $80^{\circ} \mathrm{C}$ compared to a methylene benchmark (C1-AEM). $\mathrm{H}_{2} / \mathrm{O}_{2}$ fuel cells containing C4-AEM still achieved a peak power density of $>1 \mathrm{~W} \mathrm{~cm}^{-2}$.
\end{abstract}

The use of aromatic polymer components in anion exchange membranes (AEMs) is widespread due to the availability of facile polymerisation and functionalisation procedures. However, the cationic head-groups that are covalently bound to benzylic positions are sensitive to substitution by hydroxide (leading to alkali unstable AEMs). ${ }^{1}$ The major degradation products from alkali degradation of benzyltrimethylammonium cations are benzyl alcohol and trimethylamine (from direct $\mathrm{S}_{\mathrm{N}} 2_{\mathrm{Bn}}$ mechanisms and via ylide formation). ${ }^{2,3}$ A strategy to reduce degradation via these pathways is to introduce an aliphatic (spacer) chain between the aryl and the cationic (ionexchanging) groups. As reviewed recently, ${ }^{4}$ this strategy has proven successful for a wide variety of polymers containing aromatic group, ${ }^{5-11}$ including poly(phenylene ethers), poly (phenylene) and polysulfones. In many cases, an improved ionic conductivity has also been observed on addition of spacergroups, which was ascribed to the increased mobility of the resulting quaternary ammonium-containing side-chains. ${ }^{6,12,13}$

High performance AEMs containing a methylene-(C1)-group between the benzene ring and the cationic head-group have already been prepared by radiation-induced grafting of vinylbenzyl chloride (VBC) monomer onto commodity ETFE polymer films. ${ }^{14}$ The treatment of such films in air with an $\mathrm{e}^{-}$-beam source leads to the functionalisation of the films with peroxide groups (Scheme 1). ${ }^{15}$ Heating these radiation-activated polymer films in the presence of VBC (the grafting step) produces graft

Department of Chemistry, University of Surrey, Guildford GU2 7XH, UK. E-mail: jupongon@gmail.com

$\uparrow$ Electronic supplementary information (ESI) available: Additional experimental details and data in support of the main text. See DOI: 10.1039/c7ta10222d copolymers, $\$$ which can be subsequently functionalised with amines to yield pendant quaternary ammonium groups. These AEMs give high performances in $\mathrm{H}_{2} / \mathrm{O}_{2}$ anion-exchange membrane fuel cells (AEMFCs) but they also degrade during ex situ treatment in aqueous alkali solutions at $>70{ }^{\circ} \mathrm{C} .{ }^{\mathbf{1 6 - 1 8}}$

We recently found that the efficiency of the grafting step could be increased by the use of water in the grating mixture. ${ }^{17}$ However, it still remained impossible to radiation-graft linear aliphatic monomers, such as 6-chloro-1-hexene, onto ETFE, which would have eliminated the presence of base-labile benzylic groups in the resultant AEMs: radiation-grafting is a radical polymerisation process, which enables polymerisation of styrenic monomers but not linear aliphatic vinyl monomers. As a compromise solution, a styrenic monomer was selected for

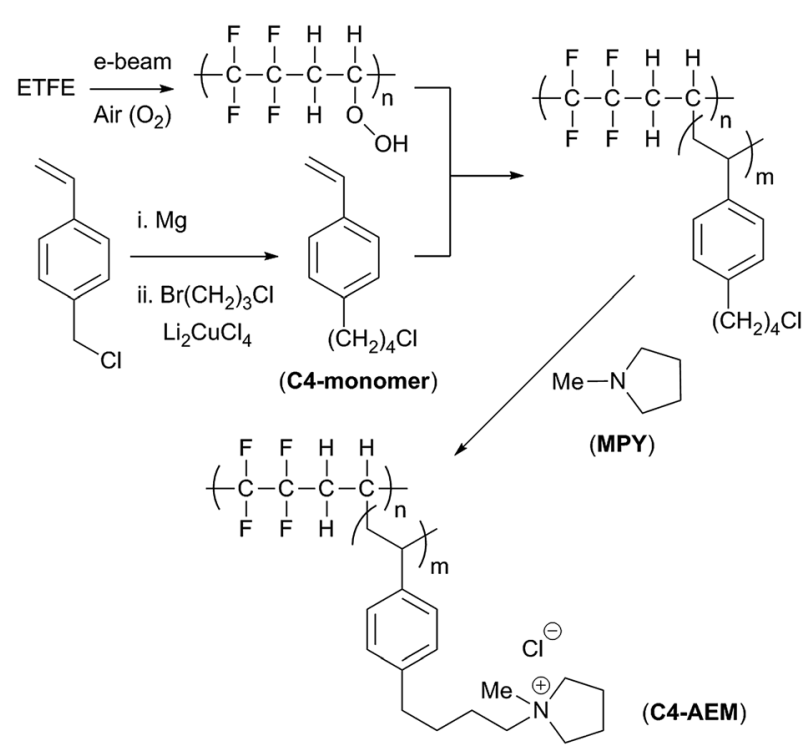

Scheme 1 An outline of the synthesis of the pyrrolidinium-graftedETFE-based C4-AEM developed in this study. The C1-AEM benchmark contains a single $-\mathrm{CH}_{2}-$ group between the benzene ring and the cationic pyrrolidinium $\mathrm{N}$-atom. 
use that contains an alkyl-spacer-chain located between the vinylbenzene group and the cationic quaternary ammonium group: this eliminates the presence of (alkali-susceptible) benzylic quaternary ammonium groups while retaining the availability of readily-polymerizable vinylbenzene groups.

In this study, we report the synthesis of a radiation-grafted AEM containing a (C4) butyl-spacer between the aromatic and quaternary ammonium groups (C4-AEM), which exhibits a reduced level of alkali degradation at $80{ }^{\circ} \mathrm{C}$. Theoretical and experimental studies on small cationic molecules have found that trimethylalkylammoniums bearing alkyl chains containing 4-6 carbon atoms in length show higher alkaline resistance than those with shorter or longer alkyl chains. ${ }^{19,20}$ We opted for a monomer, 1-(4-chlorobutyl)-4-vinylbenzene, containing a butyl-spacer located at the para-aromatic position (C4-monomer, Scheme 1), as larger monomers (e.g. with a C6-spacer) risk impeded diffusion into the ETFE films in the grafting process. The bromide form of this monomer has been previously prepared by Tomoi et al. and converted into cross-linked quaternary ammonium anion-exchange resins. ${ }^{21}$ The hydroxide form of these resins retained their ion exchange capacities at $100{ }^{\circ} \mathrm{C}$ more than the (C1-linked) benzyltrimethylammonium analogues. Despite the presence of $\mathrm{C}-\mathrm{H}$ bonds at the $\beta$-positions to the quaternary ammonium groups, these resins did not undergo high levels of the anticipated degradation via Hoffman elimination.

Tomoi et al.'s monomer synthesis involved $\mathrm{Cu}$-mediated cross-coupling of vinylbenzylmagnesium chloride with 1,3dibromopropane. ${ }^{21}$ We applied the same method using 1bromo-3-chloropropane to give 4 -(1'-chlorobutyl)styrene in $58 \%$ yield after distillation (details in the ESI $\dagger$ ). A divinyl by-product (Fig. S1 in the ESI†े), resulting from homocoupling of the vinylbenzylmagnesium chloride, was also present in $23 \%$ molar ratio in the crude reaction mixture: this could be reduced to $2 \%$ on distillation (calculated from the ${ }^{1} \mathrm{H}$ NMR spectra, Fig. S2 in the ESI†). This by-product can act as a crosslinker during the grafting step. Finally, $50 \mathrm{ppm}$ of 4-tert-butylcatechol (radical polymerisation inhibitor) was added to the monomer $(+2 \%$ crosslinker) mixture before use in the grafting step: this matched the inhibitor concentration in the commercially available VBC monomer (supplied as a mixture of para- and meta-isomers) used to produce the C1-AEM benchmark.

The grafting conditions employed were comparable to those described previously ${ }^{17}$ but with the additional use of an ultrasound bath during the grafting step. Nasef et al. recently reported that the yield and kinetics of radiation-grafting could be enhanced by the use of sonication and that this additionally reduces the formation of undesired homopolymer by-products. ${ }^{22}$ With our synthetic protocol, a comparison between ultrasound-aided and ultrasound-free radiation-grafting of VBC indicated that the use of ultrasound did not improve grafting yield but did allow a reduction in grafting time $(6 \mathrm{~h}$ with sonication vs. $16 \mathrm{~h}$ without) with the elimination of poly(VBC) homopolymer formation (previously observed as a white solid on the walls of the grafting vessel). The C4-monomer also underwent ultrasound-assisted radiation-grafting but resulted in lower grafting yields compared to the VBC, due to its higher molecular weight. Non-ultrasound grafting of C4-monomer was even less successful and led to high levels of undesired homopolymer (confirmed by Raman spectroscopy, see Fig. S3 in the ESI $\dagger$ ).

The optimum conditions for grafting C4-monomer onto ETFE films (yielding ETFE-polyC4) involved immersion of preirradiated ETFE (40 kGy in air) in $\mathrm{N}_{2}$-purged monomer-water mixtures containing the wetting agent 1-octyl-2-pyrrolidone (1\% $\mathrm{vol})$ and heating for $6 \mathrm{~h}$ at $70{ }^{\circ} \mathrm{C}$ with sonication $(35 \mathrm{kHz}, 225 \mathrm{~W})$. To account for the $28 \%$ higher molecular weight of C4-monomer, it was used at a concentration of $5 \%$ vol, while $4 \%$ vol VBC was used to synthesise the ETFE-polyVBC membrane that was then aminated to form the C1-AEM benchmark (all other grafting conditions were identical). Grafting was confirmed using Raman spectroscopy where significant differences were observed between the two monomers (Fig. 1). The benzylic $\mathrm{CH}_{2} \mathrm{Cl}$ deformation $\left(1270 \mathrm{~cm}^{-1}\right)$ was not visible in the spectrum of ETFE-polyC4. The bands characteristic of meta-disubstituted benzene rings $\left(1000 \mathrm{~cm}^{-1}\right.$ and $\left.700 \mathrm{~cm}^{-1}\right)$ were also absent, ${ }^{16,23}$ since the C4-monomer was synthesised from a paradisubstituted-only starting material. Homogeneous grafting, throughout the core of both pre-aminated membranes, was confirmed by cross-sectional Raman maps of the ratio between the areas of the $1615 \mathrm{~cm}^{-1} / 830 \mathrm{~cm}^{-1}$ bands, since these represent the aromatic ring/ETFE components, respectively (see Fig. S4 in the ESI $\dagger) .16,24$

For the amination of ETFE-polyVBC and ETFE-polyC4, to form C1-AEM and C4-AEM respectively, we selected $N$-methylpyrrolidine (MPY): this yields AEM cationic head-groups with superior alkaline stabilities and enhanced fuel cell performances compared to the traditional use of trimethylamine (TMA). ${ }^{16}$ We suspect that the reason behind the enhanced $e x$ situ stability of MPY membranes is related to their higher $\lambda_{\text {water }}$ (average number of $\mathrm{H}_{2} \mathrm{O}$ molecules per anion), being around 1.5 times those of TMA-based AEMs. ${ }^{18}$ As recently published, the number of water molecules solvating the $\mathrm{OH}^{-}$anions has a substantial effect on AEM chemical stability. ${ }^{25,26}$ Furthermore, attempts to aminate ETFE-polyC4 at room temperature with TMA proved unsuccessful due to the higher activation energies required for $\mathrm{S}_{\mathrm{N}} 2$ reactions on non-benzylic primary alkyl chlorides (the high volatility of aqueous TMA solutions impedes the

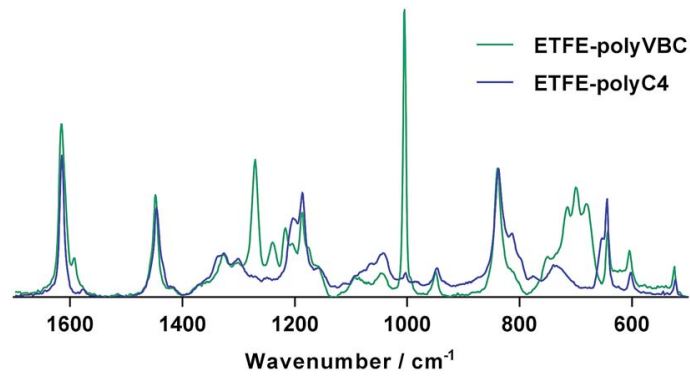

Fig. 1 Raman spectra of the pre-aminated radiation-grafted ETFEfilms synthesised using the C4-monomer and commercially available VBC (meta- and para-isomer mixture). All spectra have been normalized to the $830 \mathrm{~cm}^{-1}$ band (related to the ETFE backbone) to aid visual comparison. Laser $\lambda=532 \mathrm{~nm}$. 
use of elevated temperatures on safety grounds). A prior optimisation study for the MPY amination of ETFE-polyVBC intermediates concluded that using 15\% vol MPY in water for 6 hours at $60{ }^{\circ} \mathrm{C}$ was the mildest and cheapest effective option (details in the ESI $\dagger$ ). However, this did not translate to ETFEpolyC4 (containing lower reactivity, non-benzyl head-groups): $70{ }^{\circ} \mathrm{C}$ and $24 \mathrm{~h}$ were required with the use of aqueous MPY (15\% vol).

C4-AEM had 20\% lower ion-exchange capacity (IEC) than the C1-AEM benchmark due to its lower Degree of Grafting (DoG) (Table 1). However, the Water Uptakes (WU) and $\lambda_{\text {water values }}$ were similar for both AEMs. Likewise, no major differences in the swelling degrees and the mechanical properties were seen between the two AEMs (Tables 1, S2, Fig. S6 and S7 in the ESI $\dagger$ ). The $\mathrm{Cl}^{-}$conductivity of C4-AEM was lower than that of C1-AEM (Table 1 and Fig. S5 in the ESI $\dagger$ ) but, as expected for AEMs containing similar pyrrolidinium chemistries and $\lambda_{\text {water }}$ values, the IEC-normalised conductivities ${ }^{27}$ were similar (Fig. 2).

The $\mathrm{H}_{2} / \mathrm{O}_{2}$ AEMFC performances at $60{ }^{\circ} \mathrm{C}$ of membrane electrode assemblies (MEA) comprising both AEMs were evaluated using gas diffusion electrodes (GDEs) that contained $20 \%$ wt ETFE-benzyltrimethylammonium-based anionexchange ionomer powder ${ }^{28}$ and $80 \%$ wt electrocatalysts: the $\mathrm{Pt} / \mathrm{C}$ cathodes and PtRu/C anodes (all $0.40 \pm 0.01 \mathrm{mg}_{\mathrm{Pt}} \mathrm{cm}^{-2}$ ) were prepared as previously reported (details in the ESI $\dagger$ ). ${ }^{18}$ The low current performances of both AEMs were identical, confirming similar electrocatalytic activities (Fig. 3). However, the performance curves deviate at higher currents, where internal ohmic resistances and mass transport losses control performances. C1-AEM achieved a peak power density of $1.22 \mathrm{~W} \mathrm{~cm}^{-2}$, whereas C4-AEM obtained $1.02 \mathrm{~W} \mathrm{~cm}^{-2}$ (under identical test conditions): this $17 \%$ lower power density is still good considering C4-AEM was $26 \%$ lower in conductivity at $60{ }^{\circ} \mathrm{C}$ than $\mathbf{C 1 -}$ AEM. The peak power increased to $1.12 \mathrm{~W} \mathrm{~cm}^{-2}$ at $70{ }^{\circ} \mathrm{C}$ with C4-AEM but no further improvement was observed when raising the temperature to $80{ }^{\circ} \mathrm{C}$ (Fig. S8 in the ESI $\dagger$ ).

The ex situ chemical stabilities were tested by ageing individual samples of each AEM in aqueous $\mathrm{KOH}\left(1 \mathrm{~mol} \mathrm{dm}^{-3}\right)$ at

Table 1 Key properties of both radiation-grafted AEMs studied (errors are from repeat measurement on $n=3$ or 4 samples of each AEM: $n$ indicated in brackets)

\begin{tabular}{lll}
\hline & C1-AEM & C4-AEM \\
\hline DoG $(\%)$ & 75 & 66 \\
$\mathrm{IEC} / \mathrm{mmol} \mathrm{g}^{-1}$ & $1.92 \pm 0.05(4)$ & $1.508 \pm 0.005(4)$ \\
$\mathrm{WU}(\%)$ & $95 \pm 12(4)$ & $85 \pm 8(4)$ \\
$\lambda_{\text {water }}$ & $28 \pm 3(4)$ & $31 \pm 3(4)$ \\
$\mathrm{SD}_{x y}(\%)^{b}$ & $51 \pm 5(3)$ & $52 \pm 1(3)$ \\
$\mathrm{SD}_{z}(\%)^{c}$ & $65 \pm 6(3)$ & $59 \pm 8(3)$ \\
$\sigma_{\mathrm{Cl}}\left(60^{\circ} \mathrm{C}\right) / \mathrm{mS} \mathrm{cm}^{-1 d}$ & $41 \pm 3(3)$ & $30.4 \pm 1.3(3)$
\end{tabular}

${ }^{a}$ Average number of $\mathrm{H}_{2} \mathrm{O}$ molecules per $\mathrm{Cl}^{-}$anion calculated as: $\lambda_{\text {water }}=$ $\mathrm{WU}(\%) /(100 \times 18.02 \times$ IEC $)$, where IEC is in $\mathrm{mol} \mathrm{g}^{-1} \cdot{ }^{b}$ Swelling degree in the $x-y$ (in-plane) direction. ${ }^{c}$ Swelling degree in the $z$ (through-plane, thickness) direction. ${ }^{d}$ The $\mathrm{Cl}^{-}$anion conductivities at $60^{\circ} \mathrm{C}$ of the fully hydrated AEMs (4-probe, in-plane measurements with the RG-AEM submerged in water).

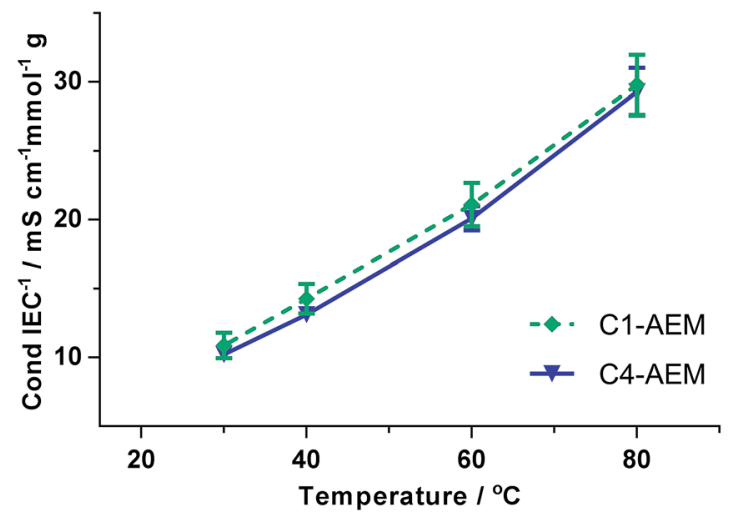

Fig. 2 IEC-normalised $\mathrm{Cl}^{-}$-anion conductivities (4-probe, in-plane, measured in water). Errors bars are from repeat measurement on $n=3$ samples of each AEM.

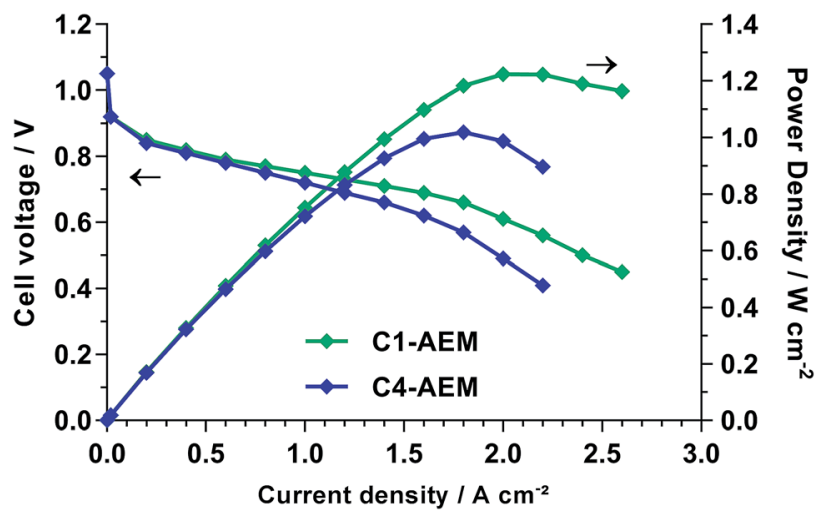

Fig. $3 \quad \mathrm{H}_{2} / \mathrm{O}_{2}$ fuel cell performances at $60{ }^{\circ} \mathrm{C}$ with $\mathrm{PtRu} / \mathrm{C}$ anodes and $\mathrm{Pt} / \mathrm{C}$ cathodes (all $0.4 \mathrm{mg}_{\mathrm{Pt}} \mathrm{cm}^{-2}$ ). The unpressurised gases were supplied at 1 SLPM and $68 \% \mathrm{RH}$.

$80{ }^{\circ} \mathrm{C}$ for $28 \mathrm{~d}$. Post-aged samples were converted back into the $\mathrm{Cl}^{-}$-form and the IECs were re-measured (Table 2). The loss of IEC with C4-AEM was half that of the C1-AEM benchmark. For more insights into the degradation mechanisms, $\mathrm{CHN}+\mathrm{Cl}$ elemental analyses were also performed (Fig. 4). The \% $\mathrm{Cl}$ loss correlates with the \% IEC loss as all degradation mechanisms lead to loss of $\mathrm{Cl}^{-}$anions. However, the differences between the $\% \mathrm{Cl}$ and \% $\mathrm{N}$ losses indicate multiple degradation mechanisms are operating (discussed previously: ${ }^{16}$ see Fig. S9 in the $\mathrm{ESI} \dagger)$.

Around a third of the degradation of C1-AEM involves loss of the $\mathrm{N}$ atoms due to $\mathrm{OH}^{-}$derived displacement of complete MPY head-groups $\left(\mathrm{S}_{\mathrm{N}} 2_{\mathrm{Bn}}\right)$. Degradation by this pathway is essentially eliminated with C4-AEM, as the partial negative charges on the $\alpha-\mathrm{C}$ atom (attached to the quaternary ammonium $\mathrm{N}$ ) are not stabilized by resonance with a phenyl ring (confirms the stabilising effect of the spacer-group). ${ }^{4}$ For C4-AEM, degradation via Hoffman elimination at the spacer-chain is also possible, which would lead to loss of $\mathrm{N}$ content: however, the near zero $\% \mathrm{~N}$ loss indicates that this, along with nucleophilic loss of MPY, does not occur to a significant extent (in accordance with Tomoi et al. .). ${ }^{21}$ Adding a spacer-chain appears to have "switched 
Table 2 The IEC values of AEM samples $(n=4)$ recorded before and after ex situ alkali ageing in aqueous $\mathrm{KOH}\left(1 \mathrm{~mol} \mathrm{dm}^{-3}\right)$ at $80^{\circ} \mathrm{C}$ for $28 d$

\begin{tabular}{lcc}
\hline & C1-AEM & C4-AEM \\
\hline${\text { IEC pre-aged AEM } / \mathrm{mmol} \mathrm{g}^{-1}}_{\text {IEC post-aged AEM } / \mathrm{mmol} \mathrm{g}^{-1}}$ & $1.88 \pm 0.03$ & $1.44 \pm 0.04$ \\
IEC loss (\%) & $1.38 \pm 0.01$ & $1.25 \pm 0.02$ \\
& $27 \pm 2$ & $13 \pm 3$
\end{tabular}

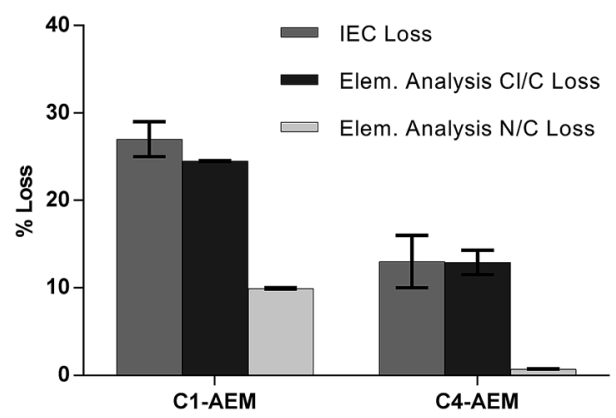

Fig. $4 \%$ loss of IEC and \% losses of $\mathrm{Cl} / \mathrm{C}$ and N/C molar ratios, the latter extracted from elemental analyses, of the AEM samples before and after ex situ alkali treatment in aqueous $\mathrm{KOH}(1 \mathrm{M})$ at $80{ }^{\circ} \mathrm{C}$ for 28 days.

off" the degradation mechanisms involving loss of $\mathrm{N}$ atoms (see the degradation mechanisms in Fig. S9 in the ESI $\dagger$ ). Nevertheless, 13\% degradation still occurs with C4-AEM, which is predominantly due to loss of positive charges (loss of $\mathrm{Cl}^{-}$ anions) but with retention of $\mathrm{N}$ atoms on the polymer grafts. This can proceed via nucleophilic substitution on the $N$-methyl group $\left(\mathrm{S}_{\mathrm{N}} 2_{\mathrm{NMe}}\right)$ or ring-opening of the 5 -membered heterocyclic ring. ${ }^{29}$ A previous study of ETFE-based VBC-grafted AEMs, with different head-groups, ${ }^{16}$ observed $12-14 \%$ degradation that did not involve loss of $\mathrm{N}$ content (approximately constant for TMA-, MPY- and $N$-methylpiperidinium-based head-groups). To obtain further confirmation of the degradation mechanisms, solid-state ${ }^{13} \mathrm{C}$ and ${ }^{14} \mathrm{~N}$ NMR spectra were recorded on the preand post-alkali-aged samples, but no discernible changes were observed on ageing (see Fig. S10 and S11 in the ESI†).

\section{Conclusions and future research directions}

The introduction of a (C4) butyl-spacer between the quaternary ammonium and the benzene rings of a ETFE-based radiationgrafted anion-exchange membrane (AEM) led to a significant enhancement in ex situ alkali stability (compared to the nonspacer methylene-(C1)-linked benchmark). A more realistic evaluation of chemical stability would involve alkali treatment of AEM samples at low relative humidity since, as recently reported, dehydration of the cathode during fuel cell operation accelerates degradation of the polymer electrolytes. ${ }^{2,26,30}$ These experiments will be considered for future, more extensive studies on these AEMs. The additional use of ultrasound during the grafting step was essential for successful synthesis of the new C4-AEM. A lower degree of grafting ( $c f$. the C1-benchmark) led to a decrease in conductivity and fuel cell performance (peak power densities still exceeded $1 \mathrm{~W} \mathrm{~cm}^{-2}$ ). Next steps involve increasing the ion-exchange capacity (degree of grafting) of the C4-spacer AEMs and development of a C4-type radiation-grafted anion-exchange ionomer powder to enable in situ fuel cell durability studies with spacer-only anion-exchange polymer electrolytes in the membrane electrode assemblies (the lack of spacer-type ionomer powders currently precludes in situ durability studies as the current non-spacer ionomer powder degrades faster).

\section{Data access}

All raw data is freely available on request: access details can be found at DOI: 10.15126/surreydata.00845195.

\section{Conflicts of interest}

There are no conflicts of interest to declare.

\section{Acknowledgements}

The research was funded by EPSRC grant EP/M005933/1. Imad thanks the University of Surrey for providing funds for his undergraduate final year project.

\section{Notes and references}

$\ddagger$ It is not currently known whether an oxygen atom (C-O-C ether group) links the ETFE backbone and the pendent grafted polymer chains or if the link is a $\mathrm{C}-\mathrm{C}$ bond. ${ }^{15}$

1 S. A. Nuñez, C. Capparelli and M. A. Hickner, Chem. Mater., 2016, 28, 2589.

2 A. D. Mohanty and C. Bae, J. Mater. Chem. A, 2014, 2, 17314.

3 M. R. Sturgeon, C. S. Macomber, C. Engtrakul, H. Long and B. S. Pivovar, J. Electrochem. Soc., 2015, 162, F366.

4 P. Jannasch and E. A. Weiber, Macromol. Chem. Phys., 2016, 217, 1108.

5 H.-S. Dang and P. Jannasch, Macromolecules, 2015, 48, 5742. 6 Z. Yang, J. Zhou, S. Wang, J. Hou, L. Wu and T. Xu, J. Mater. Chem. A, 2015, 3, 15015.

7 L. Zhu, J. Pan, Y. Wang, J. Han, L. Zhuang and M. a. Hickner, Macromolecules, 2016, 49, 815.

8 M. R. Hibbs, J. Polym. Sci., Part B: Polym. Phys., 2013, 51, 1736.

9 J. Han, Q. Liu, X. Li, J. Pan, L. Wei, Y. Wu, H. Peng, Y. Wang, G. Li, C. Chen, L. Xiao, J. Lu and L. Zhuang, ACS Appl. Mater. Interfaces, 2015, 7, 2809.

10 W. H. Lee, Y. S. Kim and C. Bae, ACS Macro Lett., 2015, 4, 814. 11 C. Xiao Lin, X. Qin Wang, E. Ning Hu, Q. Yang, Q. Gen Zhang, A. Mei Zhu and Q. Lin Liu, J. Membr. Sci., 2017, 541, 358.

12 H.-S. Dang, E. A. Weiber and P. Jannasch, J. Mater. Chem. A, $2015,3,5280$. 
13 C. X. Lin, X. L. Huang, D. Guo, Q. G. Zhang, A. M. Zhu, M. L. Ye and Q. L. Liu, J. Mater. Chem. A, 2016, 4, 13938.

14 J. R. Varcoe, R. C. T. Slade, E. Lam How Yee, S. D. Poynton, D. J. Driscoll and D. C. Apperley, Chem. Mater., 2007, 19, 2686.

15 L. Gubler, Adv. Energy Mater., 2014, 4, 1300827.

16 J. Ponce-Gonzalez, D. K. Whelligan, L. Wang, R. Soualhi, Y. Wang, Y. Peng, H. Peng, D. C. Apperley, H. N. Sarode, T. P. Pandey, A. G. Divekar, S. Seifert, A. Herring, L. Zhuang and J. R. Varcoe, Energy Environ. Sci., 2016, 9, 3724 .

17 L. Wang, E. Magliocca, E. L. Cunningham, W. E. Mustain, S. D. Poynton, R. Escudero-Cid, M. M. Nasef, J. PonceGonzález, R. Bance-Souahli, R. C. T. Slade, D. K. Whelligan and J. R. Varcoe, Green Chem., 2017, 19, 831.

18 L. Wang, J. J. Brink, Y. Liu, A. M. Herring, J. Ponce-González, D. K. Whelligan and J. R. Varcoe, Energy Environ. Sci., 2017, 10, 2154.

19 H. Long and B. S. Pivovar, J. Phys. Chem. C, 2012, 116, 9419. 20 M. G. Marino and K. D. Kreuer, ChemSusChem, 2015, 8, 513.
21 M. Tomoi, K. Yamaguchi, R. Ando, Y. Kantake, Y. Aosaki and H. Kubota, J. Appl. Polym. Sci., 1997, 64, 1161.

22 M. M. Nasef, P. Sithambaranathan, A. Ahmad and E. Abouzari-lotf, Radiat. Phys. Chem., 2017, 134, 56.

23 P. Larkin, Infrared and Raman Spectroscopy; Principles and Spectral Interpretation, Elsevier Science, 2011.

24 W. H. Lee, C. Crean, J. R. Varcoe and R. Bance-Soualhi, RSC Adv., 2017, 7, 47726.

25 D. R. Dekel, M. Amar, S. Willdorf, M. Kosa, S. Dhara and C. E. Diesendruck, Chem. Mater., 2017, 29, 4425.

26 D. R. Dekel, S. Willdorf, U. Ash, M. Amar, S. Pusara, S. Dhara, S. Srebnik and C. E. Diesendruck, J. Power Sources, 2017, 375, 351.

27 S. Gu, R. Cai and Y. Yan, Chem. Commun., 2011, 47, 2856.

28 S. D. Poynton, R. C. T. Slade, T. J. Omasta, W. E. Mustain, R. Escudero-Cid, P. Ocón and J. R. Varcoe, J. Mater. Chem. A, 2014, 2, 5124.

29 X. Dong, D. Lv, J. Zheng, B. Xue, W. Bi, S. Li and S. Zhang, J. Membr. Sci., 2017, 535, 301.

30 K. D. Kreuer and P. Jannasch, J. Power Sources, 2017, 375, 361. 